\title{
Vulnerability of the United Kingdom's food supply chains exposed by COVID-19
}

\author{
Insufficient capacity in domestic food production, just-in-time supply chains and Brexit-related labour market \\ challenges have weakened the UK's food system. Building redundancy and diversity in the food system is essential \\ for resilience in the COVID-19 recovery.
}

Philip Garnett, Bob Doherty and Tony Heron

T he UK imports almost half of its food and $84 \%$ of it is fresh fruit ${ }^{1}$. It is heavily reliant on European Union (EU) countries such as Spain for vegetables and salads, and Italy for ambient goods such as tinned tomatoes and pasta. Despite advances in supply chain technology and logistics, sourcing efficiency has paradoxically made supply chains more vulnerable to disruptions ${ }^{2}$. The length and complex networks of contemporary supply chains make them difficult to regulate and manage ${ }^{3}$. Approaches such as 'lean sourcing', just-in-time (JiT) logistics, standardized components and reductions in the supply base have tended to neglect the systemic risks caused by exogenous shocks or disruptions to supply chains $\mathbf{s}^{4,5}$. Despite its breadth and importance, research into supply chain vulnerability - exposure to serious disturbance arising from within or external to the food supply chain - and by implication supply chain resilience, is in its infancy. The COVID-19 pandemic has exposed a number of vulnerabilities in the UK food system and affords the opportunity to study how food supply chains function in crisis conditions, to identify key vulnerabilities and choke points, and to explore options for strengthening the overall resilience of the system ${ }^{6-8}$.

\section{Supply chains as complex networks} The term 'supply chain' is suggestive of a linear chain of suppliers, where one organization feeds resources or materials into another. However, with contemporary supply chains in particular, it is more accurate to consider networks of multiple and bidirectional interdependencies between organizations (nodes in the network) 9

Complex supply chain networks can also be thought of as essentially open systems, rather than isolated systems with clearly definable boundaries. Unbounded interdependence between organizations in the supply chain challenges the theoretical understanding of how supply chains operate,

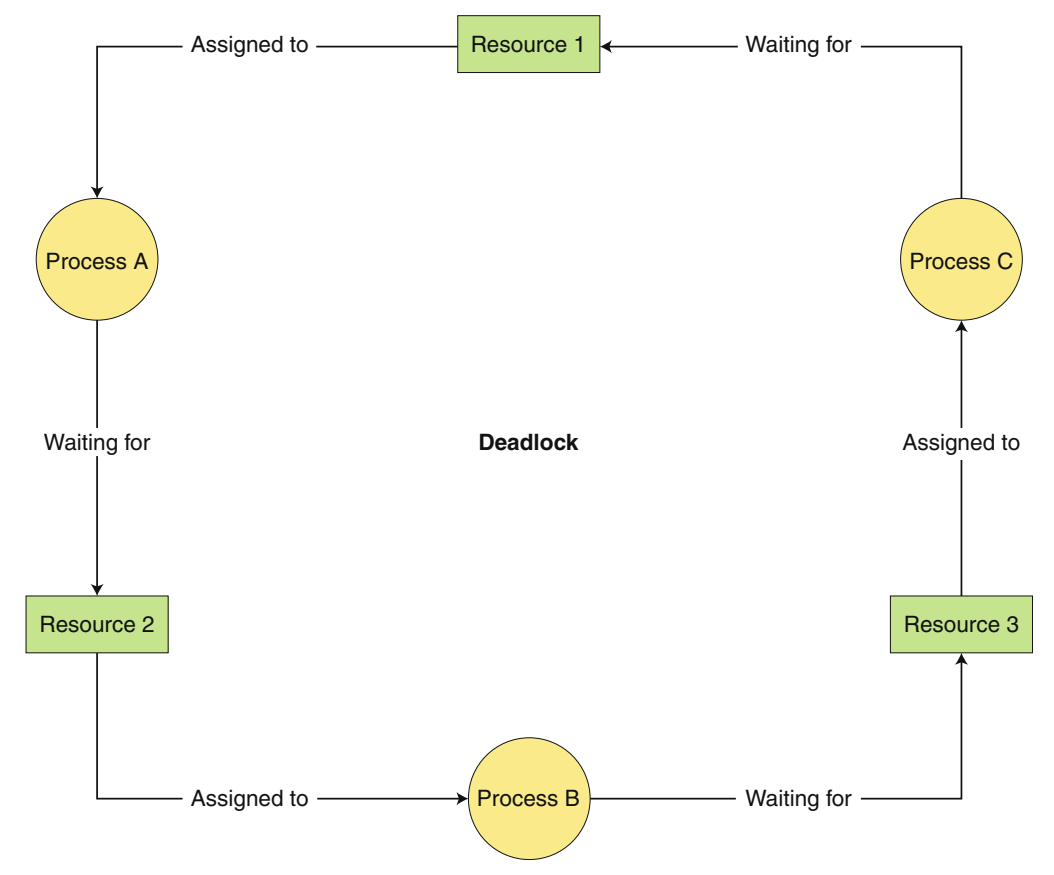

Fig. 1| Resource deadlock. All parts of the system are waiting for each other. A situation that cannot be resolved without external intervention to break the deadlock.

as it is hard to understand conceptually or computationally what the consequences for this connectivity might be $\mathrm{e}^{10}-$ particularly in terms of resilience to systemic shocks.

In situations where the supply chains operate normally, the flow of materials and resources can be close to frictionless ${ }^{11}$, and in complex supply chain networks will become highly optimized to maximize flow of resources through the system. This optimization might result in little or no redundancy at any node in the network. Though these conditions are often viewed as advantageous from the point of view of efficiency, failure in one part of a network could propagate through the (complex) network, exposing the supply chain to ripple effects ${ }^{12}$.

Tightly coupled networks may undergo failure in a number of different ways, some of which can be a consequence of the interdependencies themselves ${ }^{13}$. Failure in complex supply chain networks might also manifest as a form of deadlock, where all parts of the network are stopped waiting for resources, and the complex interdependencies between the parts (organizations and processes in the supply chains) of the network make freeing the deadlock extremely difficult (Fig. 1). This is a problem that can often be observed in computational systems, such as concurrent systems, where processes can end up deadlocked waiting for each other ${ }^{14}$.

Within food supply chains, the nature of the dependence between organizations and processes varies. Some food supply chains are highly vertically coordinated ${ }^{15}$, to move the product from source to customer as quickly as possible, although they still 
operate within and are dependent on the greater organizational network. Many food items are sourced globally (not concentrated in any one region or country) and, even if a single product is vertically coordinated, organizations in different countries are dependent on multiple, highly coordinated, global supply chains. These chains and networks are vulnerable to failures in that wider supply chain network due to loss of access to inputs or other support functions.

Food supply chains rely on a high degree of temporal coordination, based on the principles of JiT delivery to operate vertically coordinated chains from producer to customer. JiT retail-ordering systems for EU-sourced fresh fruit and vegetables work on algorithms created by the in-store electronic point of sale (EPOS) system. Typically, this creates an order in the morning, which is then placed with supermarket headquarters for example, in the UK and then before 12 noon the same day is relayed to one of their third-party suppliers in the EU27, such as Spain. The labour used to harvest and pack the product is often sub-contracted. The supermarket then expects delivery of this order at some point the next day. This is termed a 'day one for day two system's. The efficiency of this system relies heavily on frictionless trade, especially in the EU context. Food supply chain networks are therefore also temporally vulnerable - both in terms of the speed at which supermarkets rely on the delivery of products to refill shelves, but also blockages in the supply chain may render the product unusable or inedible (or both).

Supply chains are also not the only source of systemic vulnerability in food systems. Climate change is and will continue in the future to have a huge impact on the production and availability of food affecting supply, the location of production, and increasing the risks associated with extreme weather both in the $\mathrm{UK}^{16}$ and internationally ${ }^{17,18}$. Political disruptions, such as Brexit in the $\mathrm{UK}^{2}$, can also expose vulnerabilities in systems, for example, dependence on a small number of suppliers (see below). However, political risks do not only impact supply, but could also impact in other areas such as food prices ${ }^{2}$. Therefore, it is worth considering how large-scale systemic shocks, such as COVID-19, could overlap and trigger shocks elsewhere in the system, potentially exposing multiple concurrent systemic vulnerabilities and causing perturbations in the food system ${ }^{19}$.

\section{COVID-19 as a systemic shock}

COVID-19 is creating, and will continue to create, problems for food sector organizations, including disrupting their ability to produce goods and services. Reduced production in one part of the network will have knock-on effects for production elsewhere. Ordinarily, such resource issues would either be resolved quickly or the deficit would be filled by another organization in the network. COVID-19, however, might be enough of a systemic shock that mechanisms in the system that normally resolve problems can no longer function. The out-of-home sector, such as restaurants for example, has come to a halt as citizens stay indoors and rely on food retailers. Hence, suppliers are having to find new markets for their produce while some are going direct to consumers ${ }^{20}$.

As part of the drive for optimization, during the past 20 years supermarkets have reduced the diversity of their supplier base to drive efficiencies. In the case of a large, far-reaching and systemic shock such as COVID-19, the inability of suppliers to provide a diverse set of resources to complex networks of organizations can lead to large parts of the supply chain becoming deadlocked. Those resources include labour. Workforce safety concerns ${ }^{21}$ and lack of available workforce due to travel restrictions and social distancing measures ${ }^{22}$ could hold up the picking of fruits and vegetables in the EU or UK, directly affecting the supply of fresh food, but also slowing or halting the production of ambient food products such as tinned vegetables. Labour shortages impact the transport system capacity to move products due to a lack of drivers, dockworkers and infrastructure maintenance workers.

In addition, shortages of inputs for machinery, sprays, fertilizers, feeds and packaging ${ }^{23}$ could hold up a range of critical agricultural tasks such as planting, harvesting a range of key crops and lead to a reduction in yields. There are a number of points where the UK food supply chains are particularly vulnerable to problems with labour, inputs and access to services. UK food imports, for example, are heavily reliant on the Dover Strait maritime route. Ferry services between Dover and Calais and Dover and Dunkerque, and the Channel Tunnel's Freight Shuttle services between Folkestone and Calais, are the country's most significant arteries for the movement of food imports carried in accompanied road trailers. If there is disruption through one or the other route, or both, over an extended period, the alternatives are few. For the purpose-built Dover ferries and for the Freight Shuttle trains there are effectively no alternative options. The dependency of the UK distribution system is highlighted by the data in Table 1 , which shows that a

\begin{tabular}{|l|l|}
\hline $\begin{array}{l}\text { Table 1 Imports through the Dover Strait } \\
\text { Product }\end{array}$ & $\begin{array}{l}\text { Reliance on the Dover } \\
\text { Strait for EU imports (\%) }\end{array}$ \\
\hline Apples & 81 \\
\hline Pears & 57 \\
\hline Raspberries & 77 \\
\hline Strawberries & 77 \\
\hline Oranges & 81 \\
\hline Bananas & 23 \\
\hline Lettuces & 83 \\
\hline Tomatoes & 67 \\
\hline Broccoli & 74 \\
\hline Mushrooms & 39 \\
\hline Cauliflower & 74 \\
\hline Potatoes & 48 \\
\hline Pigmeat & 35 \\
\hline Poultry/meat & 59 \\
\hline Beef & 18 \\
\hline Lamb & 24 \\
\hline Cheese & 41 \\
\hline Datasho a & $2017(r+5)$ \\
\hline
\end{tabular}

Data shown are estimates for 2017 (refs. ${ }^{1,32}$ ).

large proportion of fresh foods and meat are imported via the Dover Strait network. The business objective of maintaining low stock levels, especially for short shelf-life products, based on JiT supply chain strategies, relies on the Dover Strait and Channel Tunnel routes. This therefore represents something close to a single point of failure in the UK food distribution network, potentially exposed by COVID-19.

It is also the case that a large proportion of the fruit and vegetables sold in the UK comes from a relatively small number of growing areas in Europe, particularly Andalusia and Murcia in southern Spain ${ }^{24}$. As of the time of writing, this area has not been seriously disrupted by COVID19 , although future disruption cannot be ruled out. Any significant deterioration of conditions in Spain or Italy (for ambient goods such as tinned tomatoes and pasta) could cause further and more significant disruption in the UK. The UK's lack of diversity in sourcing of products remains a point of acute vulnerability.

The concentration of international sourcing options also makes supply chains vulnerable to protectionism, as producers and supermarkets come under pressure from local populations to secure food supplies for their area ${ }^{25}$. Therefore, the failure of supply chains to distribute to places such as the UK does not have to be due to production problems or labour shortages; it could be due to societal 
problems including civil unrest ${ }^{26}$. In addition, COVID-19 has also exposed the fragilities in our food banking system, particularly in the independent food banking network, which has found it challenging to keep going, thus impacting on the supply of food to vulnerable groups $^{27}$.

\section{Food system solutions in COVID-19 recovery}

The approach of JiT supply chains, reliance on imports and diminished domestic food production has reduced the resilience of the UK food system and increased the risk of both blockages and deadlocks. Although the UK's food system has so far been proven remarkably resilient in the face of the COVID-19 shock, this resilience has benefited from a large degree of contingent luck. It remains the case that the UK is dangerously dependent on just two countries (the Netherlands and Spain) for the lion's share of its fresh vegetable imports. This dependence, moreover, relies on the frictionless trade, which the single market provides. The degree to which this dependence can be sustained after Brexit is a moot point, to say the least. The UK government in partnership with the food industry must rethink this reliance on such a vulnerable food system in the COVID19 recovery period. How the UK can grow more of its own food should be considered, and a rethink on diversifying port capacity is clearly required.

The UK must address its labour and migration policies in the agrifood sector. The UK is reliant on seasonal migrant labour to harvest domestically grown produce with 70,000-80,000 seasonal agricultural workers entering the UK every year, mainly from Romania and Bulgaria, to harvest crops. Owing to travel restrictions related to COVID-19 a huge deployment of labour from other sectors such as hospitality and perhaps incentivization of students may be required to fill this labour gap. Furthermore, there is a need for mandatory health and safety protection of workers in the food sector. Labour walk-outs could be avoided by mandatory social distancing in factories and labour force distribution combined with robust preventative measures. In the longer term, a new agricultural policy should also consider incentives to increase farm uptake of digital engagement and mechanization to drive up both sector productivity and reduce the reliance on labour.

There have been reports of states introducing emergency tariffs and export bans, especially for medical equipment, medicines, disinfectant and soap ${ }^{28}$. There were fears that Russia was close to introducing export restrictions on wheat, as it did in 2008 (ref. ${ }^{29}$ ). Although some states, including Kyrgyz Republic, North Macedonia and Thailand, have introduced temporary export restrictions on certain foodstuffs ${ }^{30}$, fears of a wider outbreak of trade protectionism have - so far - proven to be unfounded. That said, compared with the global response to the 2008 financial crisis, COVID-19 has so far prompted only limited amounts of international policy coordination. It needs to be recalled that during the financial crisis, global leadership was provided by committed multilateralists, including Barack Obama and Gordon Brown, and the rules-based system was generally in much better shape. In contrast, today's political climate is dominated by the populist nationalism associated with Donald Trump in the US and Brexit in the UK. Even in these circumstances, however, small and incremental steps could be taken towards promoting better policy coordination. This could include sharing arrangements and smarter storage capacity to build more redundancy into the system. Monitoring should be put in place to look for signs of resource deadlock internationally, with an understanding that governments might have to coordinate to facilitate the movement of resources between countries and organizations to release deadlock or mitigate its effects.

Another concern is that the COVID-19 pandemic could induce a secondary shock, such as price spikes of wheat (which may already be happening $)^{31}$. The interaction of multiple systemic shocks could also coincide. An obvious example of this would be the COVID-19 pandemic coinciding with a 'no deal' Brexit, when the current transition period ends on 31 December 2020. It is imperative that the system must be reconfigured to avoid such a failure. The COVID-19 recovery requires a focus on building redundancy and diversity in the food system, new institutional structures across the UK government, international collaborations and an investment in UK farming to boost sustainable production.

It is clear we need a new strategic plan to reorientate the UK food system to grow more food sustainably in the UK. This will require new thinking and investment in British horticulture, a crop diversification strategy, and assessment of the potential of new approaches such as indoor vertical farming. COVID-19 has also exposed the UK's vulnerability in terms of labour shortages, hence there needs to be an investment in skills and training for farming combined with investment in digital automation. The UK also needs to be a leader of international collaboration across the G7 and G20 more than ever to limit the negative consequences of protectionism. Finally, a much stronger evidence base around risk and resilience in our food system must be built across government, involving partnership at the policy-scienceindustry interface. This cannot simply be left to the market.

\section{Philip Garnett (D)', Bob Doherty (D) $1{ }^{凶}$ and Tony Heron ${ }^{2}$ \\ ${ }^{1}$ The York Management School, University of York, York, UK. ${ }^{2}$ Department of Politics, University of York, Derwent College, York, UK.

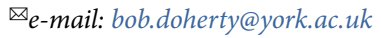

Published online: 4 June 2020

https://doi.org/10.1038/s43016-020-0097-7

\section{References}

1. Department for Environment, Food \& Rural Affairs Latest Horticulture Statistics https://go.nature.com/3dZo3cK (2018).

2. Benton, T., Froggatt, A., Wright, G., Thompson, C. \& King, R. Food Politics and Policies in Post-Brexit Britain (The Royal Institute of International Affairs, Chatham House, 2019).

3. Jackson, P. Anxious Appetites (Bloomsbury Academic, 2015).

4. Christopher, M. \& Peck, H. Int. J. Logistics Manage. 15, 1-14 (2004).

5. Lee, H. L. \& Rammohan, S. V. in Sustainable Supply Chains: A Research-based Textbook on Operations and Strategy (eds Bouchery, Y. et al.) 439-464 (Springer International Publishing, 2017).

6. Hohenstein, N.-O., Feisel, E., Hartmann, E. \& Giunipero, L. Int. J. Phys. Distribut. Logistics Manage . 45, 90-117 (2015).

7. Tukamuhabwa, B. R., Stevenson, M., Busby, J. \& Zorzini, M Int. J. Prod. Res. 53, 5592-5623 (2015).

8. Stone, J. \& Rahimifard, S. Supply Chain Manage. Int. J. 23, 207-238 (2018)

9. Hearnshaw, E. J. S. \& Wilson, M. M. J. Int. J. Oper. Prod. Manage. 33, 442-469 (2013).

10. Dubois, A., Hulthén, K. \& Pedersen, A.-C. J. Purchas. Supply Manage. 10, 3-9 (2004).

11. Yang, Z., Bonsall, S., Wall, A. \& Wang, J. WMU J. Maritime Affairs 4, 105-120 (2005)

12. Dolgui, A., Ivanov, D. \& Sokolov, B. Int. J. Product. Res. 56, 414-430 (2018).

13. Vespignani, A. Nature 464, 984-985 (2010)

14. Martin, J. M. R. \& Welch, P. H. Transputer Commun. 3, 215-232 (1997).

15. Hobbs, J. E. \& Young, L. M. Supply Chain Manage. Int. J. 5 , $131-143(2000)$

16. Benton, T. et al. Severe Weather and UK Food Chain ResilienceDetailed Appendix to Synthesis Report https://go.nature. com/3gvOTez (Biotechnology and Biological Sciences Research Council, 2012)

17. Bailey, R. et al. Extreme Weather and Resilience of the Global Food System. Final Project Report from the UK-US Taskforce on Extreme Weather and Global Food System Resilience https://go.nature.com/2Aa2wzw (The Global Food Security Programme, 2015)

18. Challinor, A. et al. UK Climate Change Risk Assessment Evidence Report: Chapter 7, International Dimensions https://go.nature. com/3cUTiWk (Committee on Climate Change, 2016).

19. Benton, T. G. \& Thompson, C. Food Sci. Technol. 30, 20-24 (2016)

20. Eley, J. UK food wholesalers move into direct selling to consumers. Financial Times https://go.nature.com/2yiaS7y (23 March 2020).

21. Canning, B. M. Staff at Moy Park walk out in dispute over coronavirus safety fears. Belfast Telegraph https://go.nature. com/2LIzx8i (26 March 2020).

22. Doward, J. Fruit and veg 'will run out' unless Britain charters planes to fly in farm workers from eastern Europe. The Guardian https://go.nature.com/2LKofk6 (28 March 2020).

23. Smithers, R. Coronavirus: UK faces cardboard shortage due to crisis. https://go.nature.com/36hT3Ce The Guardian (31 March 2020).

24. Borrás, P. Analysis: Spain rises to coronavirus challenge. Eurofruit https://go.nature.com/2ynJSUm (19 March 2020). 
25. Corona-update: French supermarkets heed the call for 'economic patriotism. Fresh Plaza https://go.nature.com/2LIBnGe (31 March 2020).

26. Giuffrida, A. \& Tondo, L. Singing stops in Italy as fear and social unrest mount. The Guardian https://go.nature.com/2zSdLwj (1 April 2020).

27. Power, M., Doherty, B., Pybus, K. \& Pickett, K. Emerald Open Res. 2, $11(2020)$.
28. International Trade Centre Market Access Map; https://go.nature. $\mathrm{com} / 2 \mathrm{TljK} 3 \mathrm{t}$

29. Trade restrictions on food exports due to the coronavirus pandemic. Reuters https://go.nature.com/2Tkqvmg (3 April 2020).

30. World Trade Organization COVID-19: Trade and Trade-Related Measures https://go.nature.com/36wC8Mg (2020).
31. Maltais, K. \& Wallace, J. Wheat and rice prices surge in coronavirus lockdown. Wall Street Journal Online https://go.nature.com/2TnER5c (30 March 2020).

32. HM Revenue \& Customs Overseas Trade Statistics; https://go.nature.com/3e8hgO9

Competing interests

The authors declare no competing interests. 